DOI: $10.14451 / 2.124 .64$

\title{
ПРОБЛЕМЫ ГОСУДАРСТВЕННОГО РЕГУЛИРОВАНИЯ ЭКОНОМИКИ РОССИИ
}

\author{
(c) 2018 Забелин Борис Фёдорович \\ кандидат экономических наук \\ Институт Промышленного Менеджмента, Экономики и Торговли (ИПМЭиТ) \\ Санкт-Петербургский политехнический университет Петра Великого (СПбПУ) \\ 195251, г. Санкт-Петербург, ул. Политехническая, д. 29 \\ E-mail: zabelinbf@mail.ru \\ (c) 2018 Никишин Вадим Михайлович \\ кандидат экономических наук, доцент \\ Санкт-Петербургский государственный электротехнический университет «ЛЭТИ» \\ им. В.И. Ульянова (Ленина) \\ 197376, г. Санкт-Петербург, ул. Профессора Попова, д. 5 \\ (c) 2018 Хатанзейский Константин Кимович \\ кандидат философских наук \\ Институт Промышленного Менеджмента, Экономики и Торговли (ИПМЭиТ) \\ Санкт-Петербургский политехнический университет Петра Великого (СПбПУ) \\ 195251, г. Санкт-Петербург, ул. Политехническая, д. 29 \\ E-mail: hatanzkk@mail.ru \\ (c) 2018 Конников Евгений Александрович \\ Институт Промышленного Менеджмента, Экономики и Торговли (ИПМЭиТ) \\ Санкт-Петербургский политехнический университет Петра Великого (СПбПУ) \\ 195251, г. Санкт-Петербург, ул. Политехническая, д. 29 \\ E-mail: konnikov.evgeniy@gmail.com
}

В рамках данной статьи авторами подробно раскрывается основные направления государственного регулирования экономики России. Авторы исследуют результаты реализации государственного регулирования экономики в рамках последнего десятилетия, описывают дуалистический характер данного процесса и прогнозируют вектор развития социальной среды России.

Ключевые слова: регулирование экономики, социальная среда, бедность, коэффициент Джини.

Необходимость государственного регулирования обусловлена объективными обстоятельствами. В развитии экономики государство призвано корректировать те недостатки, которые присущи рыночному механизму - фиаско рынка. Известно, что рынок имеет негативные стороны: он не устраняет отрицательные внешние эффекты - «экстерналии» (загрязнение окружающей среды и др.); не может регулировать использование ресурсов, принадлежащих всему человечеству; не создает стимулов для производства общественных благ; не гарантирует права на труд, доход и социальную справедливость; не обеспечивает развитие фундаментальных исследований в науке, а так же он крайне нестабилен.

Государство берет на себя ответственность за создание равных условий для сотрудничества фирм, для эффективной конкуренции, за ограничение монополизированного производства. Государству необходимо направлять экономические ресурсы на удовлетворение коллективных потребностей людей, создавать производство общественных благ. Участие государства в экономике диктуется и тем, что ему необходимо заботиться об инвалидах, детях, стариках, малоимущих, регулировать рынок труда, уровень инфляции, платежный баланс и валютный курс.

В условиях рынка государственное регулирование экономики (ГРЭ) представляет собой систему мер законодательного, исполнительного и контролирующего характера, осуществляемых государственными учреждениями с целью приспособления существующей социально-экономической системы к изменяющимся условиям рынка [10]. 
В комплексе ГРЭ различают основные методы и направления влияния государства на экономику. Выделяют административные методы регулирования и экономические, которые распадаются на прямые и косвенные. Административные методы регулирования - это антимонопольное законодательство, административные цены на стратегически важные продукты и услуги (энергоносители, транспортные тарифы, услуги ЖКХ и др.), нормы прожиточного минимума (MPOT), стандарты качества продукции и др. Решающую роль играют экономические методы. Среди них: 1) прямое регулирование экономики («потолки цен», госзаказы, госзакупки, госсектор в экономике) и 2) косвенное регулирование экономики (налоги, субсидии и др.). Основными направлениями ГРЭ являются: 1) бюджетное; 2) налоговое; 3) кредитное (регулирование ставки процента); 4) структурное (государственные целевые программы); 5) внешнеэкономическая деятельность (международная торговля, миграция рабочей силы и капиталов между странами).

Многообразие целей и задач ГРЭ реализуется через выполнение государством его основных экономических функций. К ним относятся: 1) установление правовой базы (режима) экономики с антимонопольным регулированием и защитой конкуренции; 2) макроэкономическая стабилизация; 3) оптимизация распределения ресурсов; 4) перераспределение доходов; 5) стимулирование экономического роста. В реальной действительности все функции взаимосвязаны между собой [10].

Государство, прежде всего, создает законы и правила регулирования экономики, т.е. устанавливает «правила игры». К этим правилам относятся законодательные и нормативные акты, защищающие права частной собственности, интересы всех участников рынка и государства [11]. Правовые нормы регулируют проблемы стандартов качества продукции, безопасности труда, вопросы отношений профсоюзов, администрации и др. Так, например, в России это Конституция, гражданский, трудовой, налоговый и др. кодексы и подзаконные акты, а так же деятельность арбитражных судов, силовых структур и отделов по борьбе с экономической преступностью (ОБЭП) и др.

Государство на основе антимонопольного законодательства использует меры госрегулирования, устанавливая контроль над ценами, прибегая к разделению больших фирм и препят- ствуя их слиянию.

Так, например, в России с 1995 г. действует закон о «естественных монополиях» и о «конкуренции», а также действует Федеральная антимонопольная служба ФАС по данным Росстата за 2016 г. весьма эффективно [7].

Защита конкуренции как основы рыночной экономики не сводится к регулированию правил поведения монополий и борьбы с ними. Важнейшим условием ее создания является наличие информации о ситуации на рынке и о состоянии экономики в целом, а также наличие значительного социального слоя мелких и средних частных собственников [12]. Так, например, в России в 2017 г. принята федеральная программа «Развития малого и среднего бизнеса» (субсидии, кредиты, налоговые льготы, информационная поддержка) в 82 субъектах федерации на общую сумму 7,5 млрд. руб. Но есть проблема. В 2008 г. в России зарегистрировано 8,3 млн. индивидуальных предпринимателей. В 2015 г. только 5,7 млн. Доля монополий с участием государства в ВВП России составляла в 2005 г. 35\%, а в 2015 г. около $70 \%$. Таким образом, наблюдается рост влияния монополий в экономике России, как и в других западных странах, при уменьшении конкурентных возможностей малого и среднего бизнеса и растущей роли государства [7].

Макроэкономическая стабилизация - важное направление деятельности государства, имеющее целью ликвидацию циклических колебаний экономики, обеспечение полной занятости и стабильного уровня цен. Главные инструменты в решении этой задачи - фискальная и денежно-кредитная политика. Для проведения политики стабилизации необходимо увеличивать государственные расходы и уменьшать налоги в периоды высокой безработицы или сокращать расходы и повышать налоги в периоды высокой инфляции. Регулируя денежное предложение и ставки процента, государство в лице центрального банка также может способствовать стабилизации экономики [1].

Так, например, в России ЦБ снижает ставку процента для коммерческих банков с $17 \%$ в 2014 г. до 7,5\% в 2017 г. при этом наблюдается устойчивая тенденция снижения уровня безработицы с $10 \%$ в 2000 г. до 5\% в 2017 г. и уровня инфляции с 20\% в 2000 г. до 5,4\% в 2017 г. Таким образом, намечается положительная тенденция макроэкономической стабилизации экономики России с возможными предпосылками ее эконо- 
мического роста [7].

Одним из достоинств рыночной системы является ее способность эффективно распределять ресурсы, но в некоторых ситуациях (внешние эффекты, общественные товары, несовершенство конкуренции), когда рынки действуют неэффективно, возникают проблемы, для решения которых необходимо вмешательство государства.

Регуляторами в данном случае могут быть налоги, субсидии, госзакупки и госзаказы. Они же могут воздействовать на производство общественных благ и услуг. Ведущая роль принадлежит целевым государственным программам. В России принято много целевых федеральных программ, среди которых, например: «Развитие авиационной промышленности на 2013-2025 гг.» на общую сумму 632,5 млрд. руб., «Развитие мелиорации земель сельскохозяйственного назначения на 2014-2020 гг.» на общую сумму 76 млрд. руб., «Управление федеральным имуществом 2013-2018 гг.» на общую сумму 155 млрд. руб. и др.

Объем рынка госзаказов в России в 2016 г. составлял 30 трлн. руб.т.е. 25\% ВВП из них госзакупки составляли пятую часть этой суммы. По данным Росстата доля государственного сектора в экономике с 2005 г. по 2015 г. составляла около $20 \%$, а в некоторых источниках - около 35\% [7].

Рыночный механизм не обеспечивает равенство доходов, а приводит к социальному расслоению в силу ряда обстоятельств, находящихся вне контроля человека. Государство берет на себя заботу о неимущих гражданах через налоговое перераспределение доходов в их пользу, и принимает программы их социальной защиты. Например, выплаты по соцстрахованию, медицинской помощи, пособий по безработице, определение норм прожиточного минимума и минимальных размеров оплаты труда (МРОТ). В частности показатель МРОТ в Санкт-Петербурге на 2017 г.- 16000 руб., а прожиточный минимум составил 10526 руб.

Пособие по безработице в России последние 10 лет оставалось крайне низким. Его размер колебался в интервале от 850 руб. до 4900 руб. Оно не обеспечивало замещение утраченной заработной платы даже на уровне прожиточного минимума. Более того, его размер не пересматривался, начиная с 2009 г. и не корректировался в связи с инфляцией вплоть до сентября 2018 г.

Проблема разрыва между величиной посо- бия по безработице и прожиточного минимума являлась одной из наиболее острых и актуальных социальных проблем современной России.

В 2017 г. размер прожиточного минимума был увеличен на 4,2\% и составлял 11163 руб., а в сентябре 2018 г. максимальный размер пособия по безработице планируют повысить до 8000 тыс. руб. Таким образом, наметилась положительная тенденция в решении сложной социальной проблемы [7].

В государственной политике регулирования экономического роста, можно выделить два основных направления. Первое связано с «адресным» воздействием на факторы роста и прежде всего на два главных: труд и капитал (повышение уровня образования, увеличение расходов на НИОКР и стимулирование инвестиций). Например, в России в последнее время был принят ряд федеральных программ в этой области, в частности, программа «Развитие образования в РФ 2013-2020 гг.» и программа «Информационное общество 2011-2020 гг.». При этом надо отметить, что по данным Росстата общие расходы на образование из федерального бюджета снижались с 4,6\% в 2014 г. до 3,5\% в 2017 г., что объясняется реформами высшей школы проходившими в это время, когда проявились многие кризисные явления в образовании, обусловленные отчасти сложившейся демографической ситуацией в стране [7].

Второе направление связано с проведением комплексной промышленной политики. Например, в России принят ряд комплексных программ, в частности, «Развитие промышленности и повышение ее конкурентоспособности» на общую сумму 98 млрд. руб. и «Стратегия развития автомобильной промышленности на период до 2020 г.» на общую сумму 72 млрд. руб. и др.

Для решения перечисленных задач в распоряжении государства имеется достаточно широкий набор инструментов. К ним относятся: фискальная, денежно-кредитная и социальная политика регулирования доходов.

Несмотря на имеющийся широкий набор инструментов регулирования экономического роста, надо понимать, что его проблема в России стоит достаточно остро [2]. При этом надо учитывать ряд факторов, усложняющих этот процесс. К ним относится: 1) большая протяженность территории; 2) низкий температурный режим в большей части страны; 3) сложная демографическая ситуация; 4) кризисные явления в 
образовании; 5) большие военные расходы и др. Тем не менее, по данным Росстата, например, за период с 1992 г. по 2017 г. в России среднегодовой темп роста ВВП составил - 0,64\% (12 место в мире), а в США за тот же период $-2,39 \%$ (1 место в мире). Таким образом, в России при всей сложности процесса, наблюдался экономический рост, но по сравнению с другими странами заметно его существенное отставание и замедление роста экономики в целом [7].

В процессе эволюции рыночной экономики в XX и начале XXI вв. возрастает значение социальных функций государства. Это обусловлено рядом объективных факторов:

1. Неспособность рынка обеспечить социальное равенство в обществе с точки зрения занятости и гарантированного уровня доходов.

2. Постоянные экономические кризисы сказываются, на наименее обеспеченных слоях населения и требуют ряда мер по их социальной защите.

3. Рынок неспособен создавать условия для развития отраслей социальной сферы, т.е. для общедоступного образования, культуры, здравоохранения и т.д.

Все это неизбежно усиливает социальные функции государства, заставляет его вырабатывать определенную социальную политику, которая заключается в поддержании отношений как между социальными группами, слоями общества, так и внутри них, в обеспечении условий благосостояния всех членов общества, в создании социальных гарантий [10].

Общее благосостояние зависит от доходов. Поэтому важное место в социальной политике государства занимает процесс формирования доходов населения.

Доходы - совокупность всех получаемых денежных средств, расходуемых на оплату товаров, услуг и сбережения после уплаты налогов.

Доходы населения любой страны всегда дифференцированы. Для измерения степени дифференциации в доходах используют графический показатель, получивший название кривой Лоренца.

Величина отклонения кривой от биссектрисы показывает степень неравенства в распределении доходов. Эту степень определяют при помощи индекса Джини, который изменяется в интервале от 0 (абсолютное равенство распределения доходов) до 1 (абсолютное неравенство распределения доходов). Так, например, по дан- ным Росстата этот показатель в России сильно вырос в годы реформ от 0,28 в 1992 г. до 0,4 в 1993 г. и с этого года на периоде до 2014 г. стабилизировался на уровне 0,41-0,42 (в Москве и Санкт-Петербурге - 0,5). В целом в мире можно выделить следующие зоны: 1) выравнивания доходов до 0,4 - Канада, Австралия, Индия, часть Северной Африки и Евросоюз, где лидерами являются Германия и Скандинавия; 2) умеренного неравенства доходов от 0,4 до 0,5 - США, Россия, Аргентина и некоторые страны в Африке; 3) сильного неравенства доходов более 0,5 - Китай, Мексика, север Южной Америки и юг Африки [7].

Помимо этого показателя для измерения социальной дифференциации используют децильный коэффициент. Он показывает доходный разрыв 10\% населения, имеющего наибольший уровень доходов, и 10\% населения с наименьшим его уровнем. В развитых странах он обычно составляет от 1 к 3 до 1 к 6. В России по данным Росстата этот показатель отражает негативную тенденцию в распределении доходов за последние более 20 лет, поскольку он сохранился на уровне 1 к 14,2 в 1994 г. и поднялся до рекордной отметки 1 к 16,7 в 2007 г., а в 2017 г. составил 1 к 15,5 что иллюстрирует острую социальную проблему бедности в современной России.

В цивилизованных странах разрабатывается целый ряд программ, рассчитанных на каждую категорию бедных людей [13]. В большинстве стран правительства пытаются облегчить положение бедного населения. Так, например, в России по данным Росстата число людей живущих за чертой бедности заметно сократилось с $29 \%$ населения в 2000 г. до 10,8\% в 2013 г., но с начала 2013 г. стало расти в связи с кризисными явлениями в экономике до $14,6 \%$ в 2018 г. В связи с этим Президент В.В. Путин выдвинул в качестве приоритета социальной политики государства программу борьбы с бедностью с 2018 г., согласно которой этот показатель должен сократиться в предстоящем периоде в два раза, т.е. составить $7,3 \%$.

Финансовой основой всех социальных программ является процесс перераспределения доходов путем политики их выравнивания. Практическая ее реализация связана с решением сложных проблем, так как для успешной социальной политики необходимы немалые средства. Их источник - налоги и эффективная налогово-бюджетная политика государства. В 
России по данным Минфина расходы федерального бюджета на социальную политику (включая пенсии) росли, правда, незначительно, но устойчиво с $25,1 \%$ в 2014 г. до $27,6 \%$ в 2017 г. Основными видами этих расходов являются пенсии и пособия или трансферты, т.е. выплаты из бюджета в связи со старостью, инвалидностью, смертью кормильца и др.[7].

В цивилизованных странах разрабатывается целый ряд программ, рассчитанных на каждую категорию бедных людей. Некоторые программы ориентированы на помощь детям, другие на помощь пожилым людям, есть категории дополнительных программ - для людей среднего возраста. В большинстве стран правительства пытаются облегчить положение бедного населения. Так, например, в России по данным Росстата число людей, живущих за чертой бедности, заметно сократилось с $29 \%$ населения в 2000 г. до 10,8\% в 2013 г., но с начала 2013 г. стало расти в связи с кризисными явлениями в экономике до 14,6\% в 2018 г. В связи с этим Президент В.В. Путин выдвинул в качестве приоритета социальной политики государства - программу борьбы с бедностью с 2018 г., согласно которой этот показатель должен сократиться в предстоящем периоде в два раза, т.е. составить 7,3\% [4].

Финансовой основой существования всех социальных программ является результат процесса перераспределения доходов в обществе путем проводимой государственной политики выравнивания доходов. Практическая ее реализация связана с решением сложных проблем, так как для успешного проведения социальных мер необходимы немалые средства. Их источник - налоги и эффективная налогово-бюджетная политика государства. В России по данным Минфина расходы федерального бюджета на социальную политику (включая пенсии) росли, правда, незначительно, но устойчиво с $25,1 \%$ в 2014 г. до $27,6 \%$ в 2017 г. Основными видами этих расходов являются пенсии и пособия или трансферты, т.е. выплаты из бюджета в связи со старостью, инвалидностью, смертью кормильца и др. [8].

Практика проведения социальной политики в развитых странах выработала несколько направлений ее реализации [14]. В основном она осуществляется по трем направлениям.

Первое направление характеризуется тем, что часть поступлений, получаемых населением, находится в зависимости от труда. Так, например, пенсии по возрасту и за выслугу лет. В Рос- сии в 2017 г. минимальная пенсия по возрасту составила 7800 руб., а средняя возросла с 12505 руб. в 2016 г. до 13702 руб. в 2018 г. и превысила прожиточный минимум [7].

Второе направление характеризуется тем, что выплаты не связаны с трудом их получателей, т.к., в расчет берется размер их потребностей. Например, пенсии по потере кормильца, сиротству, инвалидности и др. В России по данным Росстата пенсии по потере кормильца остаются на низком уровне, но за период с 2010 г. наметилась положительная тенденция. Эта пенсия увеличилась в два раза - с 5574 руб. до 10360 руб. в 2018 г., а пенсия по инвалидности увеличилась даже более чем в два раза с 5124 руб. в 2010 г. до 12432 руб. в 2018 г [7].

Третье направление связанно с тем, что эта часть помощи, в форме льгот и услуг, поступает населению через учреждения непроизводственной сферы. Такие доходы распределяются без учета меры труда и целиком зависят от интересов и возможностей общества на данный момент. Так, например, в России с 2007 г. действует программа «материнского (семейного) капитала» как форма поддержки семей с двумя и более детьми. Размер его вырос с 343 тыс. руб. в 2010 г. до 453 тыс. руб. в 2017 г. Он имеет целевой характер (образование, покупка жилья, а с 2018 г.автомобиль) и не обналичивается. Кроме того, в программе «Жилье для российских семей» есть льготная ипотека для многодетных семей под 6\% годовых при средней ставке 11,5\% в 2017 г. Несмотря на рост государственной поддержки детства, материнства и жилищного строительства, демографическая ситуация в стране остается сложной, поскольку данные смертности превышают рождаемость. Более того, по заявлению В.В. Путина к 2032 г. число женщин детородного возраста сократится на $25 \%$, т.е. проблема обострится [5].

Основными видами пособий в развитых странах являются: по временной нетрудоспособности, по беременности и родам, по безработице, ритуальные и др. В России, по данным Росстата, в 2018 г. все виды детских пособий колебались в интервале от 3142 руб. до 11374 руб., т.е. едва достигали прожиточного минимума, при этом максимальное пособие по безработице и на похороны составляло около половины последнего показателя до 2018 г. Таким образом, несмотря на в целом активную социальную политику государства, особенно в последние годы, 
единственно социально защищенным слоем населения в России остаются пенсионеры - участники Великой Отечественной Войны, пенсии которых в 2-3,5 раза превышают прожиточный минимум и приближаются к средней заработной плате (36 тыс. руб.), но эта часть населения незначительна и становится все меньше [7].

\section{Библиографический список}

1. Забелин Б. Ф., Никишин В.М. Монетаризм и экономика России на рубеже XXI в. //Вестник научных конференций № 9-4 (13). Тамбов. 2016.

2. Забелин Б. Ф., Никишин В.М. Монетаризм в России: проблемы совместимости. //Экономика и предпринимательство. 2016. № 11 (ч. 4). С.76.

3. Кейнс Дж. М. Общая теория занятости, процента и денег. Избранное.Москва. 2007.

4. Путин В.В.Послание Президента Федеральному Собранию от 01.03.2018 // http://kremlin.ru/events/ president/news $/ 56957$

5. Путин В.В. Прямая линия с Владимиром Путиным 07.06.2018 //https://www.1tv.ru/shows/vystupleniyaprezidenta-rossii/pryamaya-liniya-2018/pryamaya-liniya-s-vladimirom-putinym-2018-polnaya-versiya

6. Самуэльсон П. Экономикс. Избранные произведения.Москва. 1998

7. Федеральная служба государственной статистики. http://www.gks.ru/

8. Министерство финансов Российской Федерации https://www.minfin.ru/ru/

9. Фридман М. Основы монетаризма. Москва. 2002.

10. Экономическая теория. Учебное пособие/ под ред. А.А. Карачева. Санкт-Петербург. 2000.

11. Курочкина А.Ю., Голубцов С.Б., Погребова О.А. Интернет-маркетинг: учебное пособие. Санкт-Петербург. 2016.

12. Конников Е.А., Барсков В.В. Цель Российской промышленности и результаты ее достижения на современном этапе // Экономика и предпринимательство. 2015. № 11-2 (64). С. 167-170.

13. Конников Е.А., Прико П.А. Нечетко-множественная модель оценки уровня социальной ответственности организации // Экономика и предпринимательство. 2017. № 3-2 (80). С. 681-683.

14. Погребова О.А. Сегментация российских потребителей отрасли товаров и услуг здорового образа жизни // Вестник Южно-Уральского государственного университета. Серия: Экономика и менеджмент. 2015. Т. 9. № 3. C. 119-128. 